\title{
A New Method of Farming Robot
}

\author{
G. Vasumathi, J. Dhanasekar, V. Priya
}

\begin{abstract}
Agribusiness is extremely work concentrated field and just field where the robot is not utilized by and by .Presently a-days numerous ventures are attempting to diminish this human work by making machine in terms of robot. Vision based line direction of robot is finished by a strategy named as posture (having mix of picture and its ede)directs a robot in succession field. So along these lines the stage which we have executed causes the robot to utilize system named as stance for its column direction. Here we are outlining independent savvy cultivating robot which shows the plant well being by watching the shade of their leaves as far as picture preparing which is finished by raspberry pi and some confinement to plant structure. The robot additionally takes note of the encompassing natural states of the plant as far as temperature and stickiness with the goal that the robot will choose about wellbeing of plat and will show on the LCD.
\end{abstract}

Keywords: Ultrasonic principle, nimage processing

\section{INTRODUCTION}

Attempt, we will make a robot which uses vision based line course technique to go through the push crops. Over the long haul, a novel structure has been prototyped for Plant and Food Research which utilizes different electrical and PC frameworks arranging speculations. A model mechanized arm must be made, made and fabricated, which ought to be encouraged with engines, controllable utilizing explicit electronic parts and custom PC programming. Various sensors are joined into the mechanical structure counting disguising, closeness, temperature and soddenness frameworks. The structure the utilization of vision, with custom figurings being made to perceive plant headway rates. The whole structure will intertwined into a completely mechanized pack. This empowered the structure to independently return to decided goals (for example solitary plantlets) at set time between times to recognize simple changes advancement rates and leaf concealing. This gave the likelihood to plant supplement levels and the fast condition to be routinely adjusted in light of predictable distinguishing realizing propelled brisk advancement with unimportant human information. [7],[9], [10]

\section{DESCRIPTION}

Revised Manuscript Received on August 22, 2019.

G.Vasumathi Department of Mechatronics ,Bharath Institute of Higher Education \& Research,TamilNAdu Email: vasu.bala06@gmail.com

J.Dhanasekar, Department of Mechatronics ,Bharath Institute of Higher Education \& Research,TamilNAdu Email: Jdhanasekar81@gmail.com

V.Priya, Department of Mechatronics ,Bharath Institute of Higher Education \& Research,TamilNAdu Email: priyaygna14@gmail.com
For independent developing robot it required all system on robot, for that raspberry pi and ATmega8 microcontroller are utilized to perform computerized activity.

\section{SCOPE}

This venture will prompt further headway in field of farming. By decreasing human efforts in unfavorable climatic conditions, the plants well being will lie in safe hands. This project will open entryways to another mechanical progression in observation and will at last prompt advancement in agriculture field.

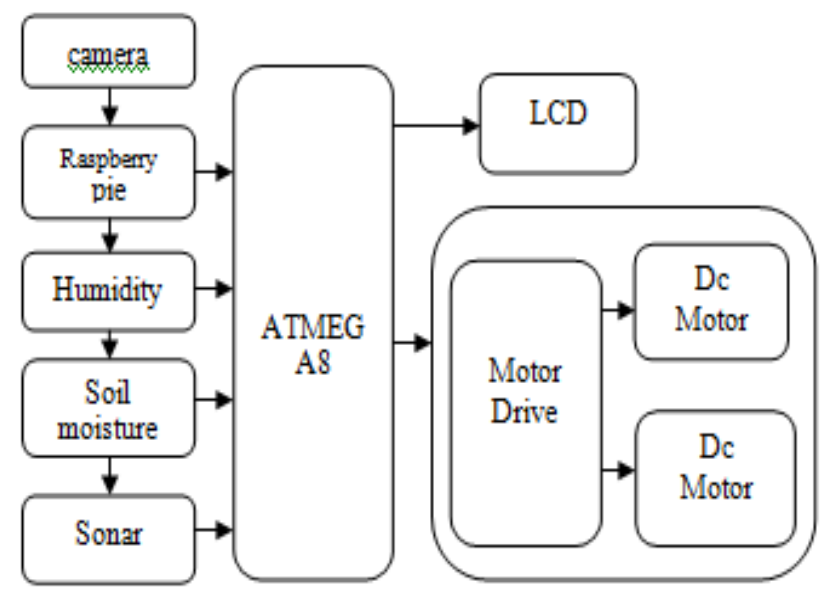

IV. STATEMENT

In this undertaking, we are attempting to build up a structure that will decrease human effort while broadening the ability of the framework. Here we are outlining out a free sharp creating robot which displays the plant flourishing by watching the shade of their leaves utilizing picture preparing. The robot besides watches the consolidating organic states of the plant like temperature, saturation and steadiness with the target that the robot will pick about nature of plant and will show up on the LCD. [1],[3],[5]

\section{BLOCK DIAGRAM}

DHT11 Temperature and Humidity Sensor highlights a temperature and stickiness sensor complex with an adjusted advanced flag yield. By utilizing the selective computerized signal acquisition technique and temperature and stickiness detecting innovation, it guarantees high unwavering quality and magnificent long term stability. [2 ],[4],[6] 


\section{A. Soil moisture sensor}

Soil dampness sensors measure the water content in soil. all plants require water to develop and survive. Soil dampness sensors used to decide how much water is expected to irrigate the plants.

\section{B. Ultrasonic}

Ultrasonic sensors produce high frequency sound waves and assess the echo which is gotten back by the sensor, measuring time interval between sending the flag and getting the resound to decide the separation to a question. [7],[9], [10]

\section{C.Camera}

It is utilized for take a picture of yields, it's straightforwardly associated with the raspberry $\mathrm{Pi}$. There region unit two courses that to append camera to raspberry Pi beginning one is USB camera and second is camera module of raspberry Pi. We watch out for territory unit exploitation camera module of raspberry pi.

\section{APPLICATIONS}

This system is used only for farming reason.

1.This system will give observation on plant wellbeing.

2.It will have relentless finding out about dampness content in the earth.

3.For a defiled plant, this system will give us the precise finding out about paying little mind to whether to CARRY on the cutting of plant leaves.

\section{FUTURE SCOPE}

1)We can build robots exactness of identification of leaf shading effectively by utilizing high quality camera.

2)Wire-less System. We can make this framework remote by utilizing RF connectors.

3)The framework can additionally altered for picking organic products, and real cutting procedure by the framework.

\section{CONCLUSION}

The proposed framework is open design so any one can make this kind of framework utilizing any way or way. The system utilizes picture handling to watch the leaf shading which increments facilitate exactness of the framework as it identifies shading precisely than human. The framework additionally watches distinctive natural conditions such as moisture, soil dampness and temperature which human can't quantify precisely by open eyes to choose the plant well being so the exactness of the framework is high. It like wise includes watering component and cutting process which decreases human work and we can lessen work advance by adjusting the frame work encourage for other farming work, for example, picking.

\section{REFERENCES}

1. Dhanasekar, J., Sengottuvel, P. \& Palanikumar, K. 2019, "Implementation of effective fuel saving methodology for turbines using air drag in vehicles", Materials Today: Proceedings, pp. 421

2. Kumar, S.S., Kumar, K.S.R. \& Kumar, N. 2018, "Experimental evaluation of magnetorheological damper characteristics for vibration analysis", International Journal of Vehicle Structures and Systems, vol. 10, no. 1 , pp. $30-34$

3. Dhamodaran, K., Adikesavana, P., Shankar, P.P. \& Gowtham, S. 2018, "Conceptual development of flapping wing for unmanned aerial vehicles: Technical note", International Journal of Vehicle Structures and Systems, vol. 10, no. 1, pp. 43-45.

4. Karthikeyan, S., Raman Balasubramanian, S.R., Ramesh, B., Raghul, S. \& Sathish Kumar, S. 2019, "The automatic solar tracker chronicles", International Journal of Recent Technology and Engineering, vol. 8, no. 1, pp. 312-315.

5. Hema, R., Sundararajan, M. \& Balaji, S. 2019, "Smartphone control robot with automatic firing gun", International Journal of Innovative Technology and Exploring Engineering, vol. 8, no. 9 Special Issue 3, pp. 625-627.

6. Balambica, V., Deepak, V. \& Kumar, S. 2019, "Design and efficiency of an asymmetric gear", International Journal of Mechanical and Production Engineering Research and Development, vol. 9, no. 3, pp. 223-230.

7. Saravana, S., Balaji, S., Arulselvi, S. \& John Paul Praveen, A. 2019, "Reliable power quality monitoring and protection system", International Journal of Innovative Technology and Exploring Engineering, vol. 8, no. 9 Special Issue 3, pp. 644-645.

8. Bycil, V.J. \& Wiselin, M.C.J. 2019, "Modeling and analysis of vibration energy harvesting system using piezo stack", International Journal of Mechanical and Production Engineering Research and Development, vol. 9, no. Special Issue 1, pp. 523-533.

9. Sripada, A., Warrier, A., Kapoor, A., Gaur, H. \& Hemalatha, B. 2018, "Dynamic lateral balance of humanoid robots on unstable surfaces", International Conference on Electrical, Electronics, Communication Computer Technologies and Optimization Techniques, ICEECCOT 2017, pp. 539.

10. Mahalakshmi, V. \& Vijayaragavan, S.P. 2019, "PV based power electronic converters for high voltage DC applications", International Journal of Recent Technology and Engineering, vol. 7, no. 6, pp. 670-674.

\section{AUTHORS PROFILE}

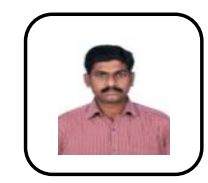

Dhanasekar. J, Assistant Professor,Department of Mechatronics Bharath Institute of Higher Education \& Research,TamilNAdu

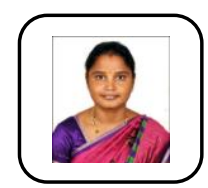

Vasumathi. Assistant, Professor,Department of Mechatronics Bharath Institute of Higher Education \& Research,TamilNAdu

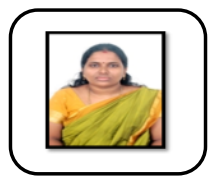

Priya V Assistant Professor,Department of Mechatronics Bharath Institute of Higher Education \& Research,TamilNAdu 